\title{
Prevalence of urinary tract infection in febrile children between one to five years of age
}

\author{
Gangina Sriram $^{1}$, Akula Satyanarayana ${ }^{2}$, Naik D.R. ${ }^{3}$, T Jaya Chandra ${ }^{4}$ \\ ${ }^{1}$ Dr. Gangina Sriram, Associate Professor, ${ }^{2}$ Dr. Akula Satyanarayana, Assistant Professor, ${ }^{3}$ Dr. Dumavath Raveendra \\ Naik, Resident, ${ }^{1,2,3}$ authors are Department of Paediatrics, ${ }^{4}$ Dr. T Jaya Chandra, Scientist Incharge, Central Research \\ Laboratory, GSL Medical College, Rajahmundry, Andhra Pradesh, India
}

Corresponding Author: Dr Akula Satyanarayana, Assistant Professor, Department of Paediatrics, GSL Medical College, Rajahmundry, Andhra Pradesh, India. E-mail: gslcentralresearchlab@gmail.com

\begin{abstract}
Introduction: It is essential to identify urinary tract infection (UTI) in febrile children and institute prompt treatment to reduce the potential for lifelong morbidity. With this a study was taken to find the prevalence of UTI in febrile children one year to five years of age. Materials and Methods: Study was conducted in GSL Medical College. Febrile children aged 1 year to 5 years attending the outpatient department or admitted in the hospital were included in the study. Socioeconomic status was categorized as per modified kuppuswamy scale. The fresh urine sample was subjected for urinalysis and culture and sensitivity. Chi-square test was used to assess the association between different categorical variables; $P<0.05$ was considered statistically significant. Results: Total 200 participants were included with male female ratio 0.87. Maximum cases were in lower middle class and nil participants in upper class. Significant pyemia was detected $13.5 \%$ (27) cases, statistically the difference was not significant $(P>0.05)$ and culture positivity was $8 \%(16)$; Esch. coli was the predominant pathogen, followed by Klebsiella pneumoniae, Pseudomonas aeruginosa and serratia spp. Conclusion: The culture positivity was $8 \%$ which is significant in the pediatric group. Hence any child with fever, UTI also should be suspected.
\end{abstract}

Keywords: Infection, Febrile, Urinary tract infection

\section{Introduction}

Children with fever comprise a substantial proportion of the practice in outpatient department and emergency medicine. Fever is the most common reason for children 1-5 years of age to visit emergency / outpatient departments. Unlike occult bacteremia or severe bacterial illness (in children) little attention has been focused on the identification of urinary tract infections (UTI) in febrile children in the emergency department, despite recent information that suggests a high prevalence of urinary tract infections and significant associated morbidity in these patients.

Quite often, child receives antibiotics empirically, without adequate evaluation for urinary tract infection. Fever, however, is often the only symptom in children with urinary tract infections.

Manuscript received: $25^{\text {th }}$ September 2019 Reviewed: $5^{\text {th }}$ October 2019

Author Corrected: $10^{\text {th }}$ October 2019

Accepted for Publication: $15^{\text {st }}$ October 2019
UTI affects approximately $7 \%$ to $8 \%$ of girls and $2 \%$ of boys during the first 8 years of life. Fever and significant bacteriuria, pyuria in children with undocumented sources of infections must be presumed to be symptoms of acute pyelonephritis (APN), an invasive infection of the renal parenchyma requiring prompt treatment $[1,2]$.

High fever with temperature of $39.5^{\circ} \mathrm{C}$ or more is the single best predictive parameter $[3,4]$. The risk of APN increases when bladder infection occurs in patients Vesicoureteral reflux (VUR), because colonized lower tract urine then has direct retrograde access to the upper tract [5].

It is essential to identify UTIs in febrile children and institute prompt treatment to reduce the potential for lifelong morbidity. With this a study was taken to find the prevalence of UTI in febrile children one year to five years of age. 


\section{Materials and Methods}

Study was conducted in the department of paediatrics, GSL Medical College from January 2014 to January 2015 Study protocol was approved by the institutional ethical committee. Informed written consent was taken from the parents of all the participants.

Inclusion criteria: Febrile children aged 1 to 5 years attending the outpatient department or admitted in the hospital were included in the study.

Exclusion criteria: Children on antibiotics 48 hours prior to the sample collection and those with known congenital genitourinary anomalies were not included in the study.

Sampling method: Random sampling technique was followed in this research; during the study period, the children who come to the pediatric department, fit inclusion criteria were considered.

A complete history related to the onset, duration of fever and associated symptoms such as nausea, vomiting, diarrhea, pain abdomen, urinary disturbances, other systems involvement was obtained. Socioeconomic status was categiorised as per modified kuppuswamy scale [6]. A thorough physical examination with relevant investigations was carried out in all patients. Routine urine analysis and culture sensitivity was done. Suprapubic aspiration and mid stream urine sample were collected based on the child response.

The fresh urine sample was subjected for urinalysis and culture and sensitivity. Urine was centrifuged at 2500 rpm for 20-30 min, supernatant was decanted and sediment was examined under microscope for hematuria, and leukocyturia. Presence of $\geq 5$ pus cells/HPF in a centrifuged urine sample was taken as significant pyuria. Culture and sensitivity was performed in that patient as per the standard practice [7].

Statistical analysis: Statistical analysis was done by using SPSS software version 21.0. Chi-square test was used to assess the association between different categorical variables; $P<0.05$ was considered statistically significant.

\section{Results}

In the present study, total 200 participants were included, $93(46.50 \%)$ were males, $107(53.50 \%)$ were females; 89 $(44.5 \%)$ cases were $<2$ years. Maximum cases for the study of urinary tract infection were in the age $<3$ years $(75 \%)$. Minimum age in the study group was 1 year and maximum age in the study group was 5 years (Table 1).

Table-1: Age, gender wise distribution of study participants; $\mathbf{n}(\%)$

\begin{tabular}{|c|c|c|c|}
\hline Age in months & Male & Female & Total \\
\hline $12-24$ & $32(18)$ & $57(28.5)$ & $89(44.5)$ \\
\hline $25-36$ & $42(21)$ & $19(9.5)$ & $61(30.5)$ \\
\hline $37-48$ & $10(5)$ & $16(8)$ & $26(13)$ \\
\hline $49-60$ & $9(4.5)$ & $15(7.5)$ & $24(12)$ \\
\hline Total & $\mathbf{9 3}(\mathbf{4 6 . 5})$ & $\mathbf{1 0 7}(\mathbf{5 3 . 5})$ & $\mathbf{2 0 0}(\mathbf{1 0 0})$ \\
\hline
\end{tabular}

Table-2: Gender wise socioeconomic status distribution among the study participants; n (\%)

\begin{tabular}{|c|c|c|c|}
\hline Class & Male & Female & Total \\
\hline Upper class & 0 & 0 & 0 \\
\hline Upper middle & $14(7)$ & $10(5)$ & $24(12)$ \\
\hline Lower middle & $40(20)$ & $50(25)$ & $90(45)$ \\
\hline Upper lower & $33(16.5)$ & $35(17.5)$ & $68(34)$ \\
\hline Lower & $6(3)$ & $12(6)$ & $18(9)$ \\
\hline Total & $\mathbf{9 3}(\mathbf{4 6 . 5})$ & $\mathbf{1 0 7}(\mathbf{5 3 . 5})$ & $\mathbf{2 0 0}(\mathbf{1 0 0})$ \\
\hline
\end{tabular}

Pediatric Review: International Journal of Pediatric Research Available online at: www.medresearch.in 543|P a g e 
Table-3: Age wise pyuria among the gender in the study participants; $n$ (\%)

\begin{tabular}{|c|c|c|c|}
\hline Age in months & Male & Female & Total \\
\hline $12-24$ & $4(15)$ & $7(26)$ & $11(41)$ \\
\hline $25-36$ & $3(11)$ & 4 (14.7) & $7(26)$ \\
\hline $37-48$ & $3(11)$ & $3(11)$ & $6(22)$ \\
\hline $49-60$ & $1(3.7)$ & $2(7.4)$ & $3(11)$ \\
\hline Total & $11(41)$ & $16(59)$ & $27(100)$ \\
\hline
\end{tabular}

Table-4: Distribution of urine culture among the study participants; $\mathbf{n}(\%)$

\begin{tabular}{|l|c|c|c|}
\hline Culture Report & Male & Female & Total \\
\hline No growth/ Contaminated & $8(30)$ & $8(30)$ & $16(60)$ \\
\hline Esch. coli & 0 & $6(22)$ & $6(22)$ \\
\hline Klebsiella & $1(3.7)$ & $1(3.7)$ & $2(7.4)$ \\
\hline Pseudomonas aeruginosa & $1(3.7)$ & $1(3.7)$ & $2(7.4)$ \\
\hline Serratia species & $1(3.7)$ & 0 & $1(3.7)$ \\
\hline Total & $\mathbf{1 1 ( 4 1 )}$ & $\mathbf{1 6 ( 5 9 )}$ & $\mathbf{2 7 ( 1 0 0 )}$ \\
\hline
\end{tabular}

According to Modified Kuppu Swamy scale, 24 (12\%) were belong to upper middle, 90 (45\%) lower middle, 34\% (68) upper lower class and (18\%) belong to lower class. However none of the participants belong to upper class. Gender wise, majority of female children belong to lower middle (45\%) and upper lower class (34\%) and in male category also, (Table 2)

In the present study, 27 children (13.5\%) showed pyuria in centrifuged urine sample; among these, $41 \%$ (11) were males and 59\% (16) were female participants; statistically the difference was not significant (Table 3); majority (40.74\%) were between 1-2 years of age.

Growth $>10^{5} \mathrm{CFU} / \mathrm{ml}$ of single organism was considered as significant bacteriuria. Culture positivity was $59.25 \%$, in this Esch. coli was the predominant (22\%) isolate, followed by Klebsiella, Pseudomonas aeruginosa (2\% each respectively) and serratia (3.7\%) species (Table 4).

\section{Discussion}

UTIs are common, potentially serious infections of childhood. UTI may lead to renal scarring, hypertension, and end stage renal disease. UTI mainly due to the ascending infection from urethra descending due to hematogenous route. The diagnosis of UTI in young children is important as it may be the marker of urinary tract abnormalities. Early diagnosis is important to preserve renal function of the growing kidney.

UTI is one of the most important risk factor in development of renal insufficiency or end stage renal disease. Among the pyogenic cases in this study, 41\% (11) cases were male and 59\% (16) were female participants (Table 3). This prevalence is comparable to many studies Shaikh $\mathrm{N}$ et al., [8] and Bauchner et al. [9], showed prevalence range from $1.2 \%$ to $8 \%$. As per Almofarreh $\mathrm{M}$ et al. study, gender is the commonest influencing factor of UTI [10]; the studies also reported that the prevalence of UTI is more in female children
$[11,12,13]$. The anatomical structure as well as less distance with anal region is the main reported cause for more prevalence of UTI among female children. In this study prevalence of UTI in 1-2 years age group was $2 \%$ which was similar to P.R Srivasths et al., [14] reported $2.5 \%$ prevalence in children $<2$ years which was lowest reported from a developing country where as Roberts et al., [15] reported 4.1\%. When age was considered, highest prevalence was reported to be highest during the first month of life [16]. M.H. Fallahzadeh et al., [17] estimated prevalence of UTIs in preschool children and reported a prevalence of $4.4 \%$. It is estimated that at least $1 \%$ of boys and $3 \%$ of girls develop UTI during first 10 years of life [18].

In young children with fever the prevalence of UTI in children $<2$ years presenting with fever has been the subject of several large prospective studies and a metaanalysis [19]. Presence of pus cells in urine, pyuria, 
detection by urine microscopy is a simple exercise. In this report, pyuria was detected in $13.5 \%$ (27) participants. Sandoval et al. reported that the sensitivity of pyuria was just $40 \%$ only in the diagnosis of UTI $[20,21]$. Studies reported that Nitrate reduction test is a better and simple diagnostic technique for the diagnosis of UTI [22]; however, it was not performed in the current study.

According to Arvind Bagga et al., [23] about 90\% of first symptomatic UTI and $70 \%$ of recurrent infections are due to Escherichia coli, followed by other bacteria such as proteus, Klebsiella and Staphylococcus saprophyticus. In this study also, Esch. coli was the predominant pathogen isolated. As per Sobel et al. [24] Serratia and Pseudomonas aeruginosa were the common pathogens cause UTI in pediatric group. Hillary L. Copp and Bogdana Schmidt [25] reported that Esch.coli is the commonest UTI causing microorganism followed by Enterobacter, Enterococcus, Klebsiella.

When socioeconic status was considered, UTI is common in lower middle (90), upper lower (68) and lower class (18) and upper middle class (24). In the literature, no studies were found on UTI correlated with socioeconomic status in this area. Lack of personal hygiene and malnutrition are the main reasons for more UTI in low socioeconomic classes.

Small sample size, lack of inpatient and outpatient correlation, lack of antibiotic susceptibility testing are the limitations of this study.

\section{Conclusion}

The culture positivity was $8 \%$ which is significant in the pediatric group. Hence any child with fever, UTI also should be suspected.

\section{What the study adds to the existing knowledge?}

The present study established more efficiently that UTI should identified and considered as a common infection in lower socioecomic category.

\section{Author's contributions}

- Dr. Gangina Sriram: Literature survey, Paper writing

- Dr. Akula Satyanarayana: Literature survey

- Dr. Dumavath Raveendra Naik: Sample collection, analysis

\section{Original Research Article}

- Dr. T Jaya Chandra: Bench work, statistical analysis, paper writing

Funding: Nil, Conflict of interest: None initiated, Permission from IRB: Yes

\section{References}

1. Hellström A, Hanson E, Hansson S, Hjälmås K, Jodal $\mathrm{U}$. Association between urinary symptoms at 7 years old and previous urinary tract infection. Arch Dis Childhood. 1991;66(2):232-234. doi: 10.1136/adc. 66 . 2.232 .

2. Mårild $\mathrm{S}$, Jodal $\mathrm{U}$. Incidence rate of first-time symptomatic urinary tract infection in children under 6 years of age. Acta Paediatrica. 1998;87(5):549-552. doi: https://doi.org/10.1111/j.1651-2227.1998.tb01502.x.

3. Pecile P, Miorin E, Romanello C, Vidal E, Contardo M, Valent F, Tenore A. Age-related renal parenchymal lesions in children with first febrile urinary tract infections. Pediatr. 2009;124(1):23-29. doi: https:// doi.org/ 10.1542/peds.2008-1192

4. Shaikh N, Ewing AL, Bhatnagar S, Hoberman A. Risk of renal scarring in children with a first urinary tract infection: a systematic review. Pediatr. 2010;126 (6):1084-1091. doi: 10.1542/peds.2010-0685. Epub 2010 Nov 8.

5. Hudson RG, Lessons from the guidelines: understanding evidence-based vesicoureteral reflux treatment in 2010. Dial Pediatr Urol. 2010; 32:5-6.

6. Oberoi SS. Updating income ranges for Kuppuswamy's socio-economic status scale for the year 2014. Indian J Pub Health. 2015;59 (2):156-157. doi: 10.4103/ 0019-557X.157540.

7. Chandra TJ, A study on isolation and identification of nosocomial infections causing bacteria on mobile phones of health care workers. Calicut Med J 2011; 9(1): e2.

8. Shaikh N, Morone NE, Bost JE, Farrell MH. Prevalence of urinary tract infection in childhood: a meta-analysis. Pediatr Infect Dis J. 2008;27(4):302-308. doi: 10.1097/INF.0b013e31815e4122.

9. Bauchner H, Philipp B, Dashefsky B, Klein JO. Prevalence of bacteriuria in febrile children. Pediatr Infect Dis J. 1987;6(3):239-242. doi: 10.1097/ 00006454- 198703000-00004. 


\section{Original Research Article}

10. Almofarreh M, Alowaa Z, Junainah E, Alshahrani N, Alharbi M, Alkhalifah W et al. Prevalence of urinary tract infection among children. Int J Contemp Pediatr. 2018;5(6):2356-2359. doi: http://dx.doi.org/10.18203/ 2349-3291.ijcp20183878.

11. Shaw KN, Gorelick M, McGowan KL, Yakscoe NM, Schwartz JS. Prevalence of urinary tract infection in febrile young children in the emergency department. Pediatr. 1998;102(2):e16. doi: 10.1542/peds.102.2.e16.

12. Newman TB, Bernzweig JA, Takayama JI, Finch SA, Wasserman RC, Pantell RH. Urine testing and urinary tract infections in febrile infants seen in office settings: the Pediatric Research in Office Settings' Febrile Infant Study. Arch Pediatr Adolesc Med. 2002;156(1):44-54. doi:10.1001/archpedi.156.1.44.

13. Zorc JJ, Levine DA, Platt SL, Dayan PS, Macias $\mathrm{CG}$, Krief $\mathrm{W}$, et al. Clinical and demographic factors associated with urinary tract infection in young febrile infants. Pediatrics. 2005;116(3):644-648. doi: 10.1542/peds.2004-1825.

14. Srivaths PR, Rath B, Krishan Prakash S, Talukdar B. Usefulness of screening febrile infants for urinary tract infection. Indian Pediatr. 1996;33(3):218-220.

15. Roberts KB, Charney E, Sweren RJ, Ahonkhai VI, Bergman DA, Coulter MP, et al. Urinary tract infection in infants with unexplained fever: a collaborative study. J Pediatr. 1983;103(6):864-867. doi: 10.1016/s00223476(83)80702-1.

16. Roberts KB. Urinary tract infection: clinical practice guideline for the diagnosis and management of the initial UTI in febrile infants and children 2 to 24 months. Pediatr. 2011;128(3):595-610. doi: 10.1542/ peds.2011-1330. Epub 2011 Aug 28.

17. Fallahzadeh MH, Alamdarlu HM. Prevalence of urinary tract infection in pre-school febrile children. Iranian J Med Sci. 1999; 24:35-39.
18. Swerkersson S, Jodal U, Åhrén C, Sixt R, Stokland E, Hansson S. Urinary tract infection in infants: the significance of low bacterial count. Pediatr Nephrol. 2016;31(2):239-245. doi: 10.1007/s00467-015-3199-y. Epub 2015 Sep 10.

19. Zafriri D, Oron Y, Eisenstein BI, Ofek I. Growth advantage and enhanced toxicity of Escherichia coli adherent to tissue culture cells due to restricted diffusion of products secreted by the cells. J Clin Invest. 1987;79(4):1210-6. doi: 10.1172/JCI112939.

20. Sandoval C, Sinaki B, Weiss R, Munoz J, Ozkaynak $\mathrm{MF}$, Tugal $\mathrm{O}$, et al. Urinary tract infections in pediatric oncology patients with fever and neutropenia. Pediatr Hematol Oncol. 2012;29(1):68-72. doi: 10.3109/ 08880018. 2011.617809.

21. Klaassen IL, de Haas V, van Wijk JA, Kaspers GJ, Bijlsma M, Bökenkamp A. Pyuria is absent during urinary tract infections in neutropenic patients. Pediatr Blood Cancer. 2011;56(5):868-870. doi: 10.1002/pbc. 22799. Epub 2010 Oct 14.

22. Christopher D Doern, Susan E. Richardson. Diagnosis of Urinary Tract infections in Children. J Clin Micro. 2016;54(9):2233-2242. doi: 10.1128/ JCM.00189-16.

23. Bagga A, Sharma J. Urinary tract infections clinical features, evaluation and treatment. Pediatr today. 2000; $3: 395-401$

24. Sobel JD. Pathogenesis of urinary tract infection. Role of host defenses. Infect Dis Clin North Am. 1997;11 (3):531-549. doi: https://doi.org/10.1016/ S0891 -5520 (05)70372-X.

25. Schmidt B, Copp HL. Work-up of Pediatric Urinary Tract Infection. Urol Clin North Am. 2015;42(4):519526. doi: 10.1016/j.ucl.2015.05.011.

\section{How to cite this article?}

Gangina Sriram, Akula Satyanarayana, Naik D.R., T Jaya Chandra. Prevalence of urinary tract infection in febrile children between one to five years of age. Int J Pediatr Res.2019;6(10): 542-546.doi:10.17511/ijpr.2019.110.08 